\title{
MEMORIES OF STEVE FIENBERG
}

\author{
REBECCA CARTER STEORTS
}

Duke University

In 2015, Steve and I traveled together to Ithaca from Pittsburgh for a workshop on differential privacy (DP). This is one of my fondest memories with Steve for many reasons. The trip involved many of my favorite things, which Steve and I both shared - statistics, hockey, great food, and good conversation. For me, this is one of my most memorable trips with Steve, as I learned so much from our conversations together.

The trip started with Steve picking me up at my apartment in Shadyside. We started our long journey in the afternoon. As the car pulled out of the driveway, you could hear the announcers yelling in the background, hockey sticks banging back and forth, and if you knew Steve well, then you knew of course the Penns were playing. So, we pulled off and mostly in silence for the first part of our journey, both hoping that the Penns would pull out a victory. After a bit, we stopped for a quick bite to eat and then resumed our drive.

For the second part of the trip, we agreed that I would drive this stretch. It was during this part of the drive that Steve and I had this very long discussion about record linkage and differential privacy. We had a long discussion regarding the history of DP, the challenges of working in a DP framework, and open problems in the field. This was quite useful for me as it enabled me to understand the entire landscape of DP without having to worry about the minute details. It's been even more helpful as I have worked on trying to make DP methods work in practice for sparse contingency tables with former MS student Bai Li and my collaborators Vishesh Karwa and Sesa Slavković.

After our research conversation, we listened to the news and Steve read his newspaper. It reminded me of earlier days when I would take road trips with my father, who would also sit in the passenger side of the car and read the newspaper. Steve would look over the newspaper from time to time and his eyes would wander over the speedometer. He would then say "watch the speed," and then he would go back to reading. Later on, we listened to some music from a band that one of his neighbors was in. They were quite good and I remember thinking how fun the music was to drive to. We eventually made it from Pittsburgh to lthaca and this is one of my most memorable times with Steve.

All in all, it was wonderful to see this other side of Steve. As I came to learn, he was one of the kindest people I knew, he was extremely trustworthy, and he was a true friend in addition to being one of the best researchers our field has ever seen. I feel so fortunate each day that I was able to be his collaborator, his mentee, and his friend. He's missed each and every day, but his memory will always go on.

Beka Steorts

Key words and phrases: reminiscences, Fienberg.

$$
\begin{array}{ll}
P_{\text {rivacy }} & \text { www.journalprivacyconfidentiality.org } \\
\text { DOl:10.29012/jpc.709 }
\end{array}
$$

This work is licensed under the Creative Commons License Attribution-NonCommercial-NoDerivatives 4.0 International (CC BY-NC-ND 4.0). To view a copy of this license, visit https: //creativecommons . org/licenses/by-nc-nd/4.0/ or send a letter to Creative Commons, 171 Second St, Suite 300, San Francisco, CA 94105, USA, or Eisenacher Strasse 2, 10777 Berlin, Germany 